\title{
Comparative Study of Growth and Gonad Maturation in Diploid and Triploid Marine Medaka, Oryzias dancena
}

\author{
In-Seok Park ${ }^{1}$, Hyun Woo Gil ${ }^{1}$, Tae Ho Lee ${ }^{1}$, Yoon Kwon Nam² and ${ }^{\dagger}$ Dong Soo Kim $^{2}$ \\ ${ }^{I}$ Division of Marine Bioscience, College of Ocean Science and Technology, Korea Maritime and Ocean University, \\ Busan 49112, Korea \\ ${ }^{2}$ Institute of Marine Living Modified Organism (iMLMO), Pukyung National University, Busan 48513, Korea
}

\begin{abstract}
The marine medaka, Oryzias dancena is a suitable sample as a laboratory animal because it has a small size and clearly distinguishes between female and male. Data on the growth and maturity of the diploid and triploid sea cucurbit species suitable for laboratory animals are very useful for studying other species. Triploidy was induced in the marine medaka by cold shock treatment $\left(0^{\circ} \mathrm{C}\right)$ of fertilized eggs for $45 \mathrm{~min}$, applied two minutes after fertilization. The diploid and triploid male fish were larger than their female counterparts $(P<0.05)$, and the concentrations of thyroid stimulating hormone (TSH) and thyroxine (T4) were higher in the induced triploids over 1 year $(P<0.05)$. In both the diploid and tri-ploid groups the concentrations of TSH and T4 were higher in the male fish than in the females $(P<0.05)$, while the testo-sterone and estradiol-17ß concentrations in the induced triploids were lower than in the diploids $(P<0.05)$. The gonadosomatic index (GSI) of the triploid fish was lower than that for the diploids, and the GSI for females in each ploidy group were higher than that for the males. For both groups the GSI was highest at 4 months of age, and decreased thereafter to 12 months. Analysis of the gonads of one-year-old triploid fish suggested that the induction of triploidy probably causes sterility in this species; this effect was more apparent in females than in males.
\end{abstract}

Key words : Growth hormone, Marine medaka, Oryzias dancena, Sex hormone, Sterility, Triploid

\section{INTRODUCTION}

The marine medaka, Oryzias dancena, is a truly euryhaline teleost fish, having a great capacity for hypo- and hyper-osmoregulation. Most of its physiological attributes are similar across a wide spectrum of salinities, ranging from fresh water to normal seawater (Inoue \& Takei, 2003; Kang et al., 2008; Cho et al., 2010). Therefore, much attention has been directed at extending the utility of functional transgenic marine medaka strains for ornamental purposes, because they can be used at most naturally oc- curring salinities (Cho et al., 2011). In addition, in a recent study of transgenic marine medaka containing the myosin light chain-2 (mlc2f) promoter, the expression of a vivid red fluorescent color in their fast skeletal muscles suggested great potential for these as novel ornamental fish for both freshwater and seawater aquaria (Cho et al., 2012). Triploidization is a technique used to generate sterile aquatic animals by taking advantage of the incompatibility in pairing the three homologous chromosomes during meiosis I (Don \& Avtalion, 1986). This technique has also been used to enhance the productivity of several fish spe-

\footnotetext{
Manuscript received October 20, 2016, Received in revised form November 19, 2016, Accepted December 12, 2016

${ }^{\dagger}$ Corresponding Author : Dong Soo Kim, Institute of Marine Living Modified Organism (iMLMO), Pukyung National University, Busan 48513, Korea. Tel. : +82-51-629-7066, Fax : +82-51-629-7067, E-mail : dongskim@pknu.ac.kr
}

This is an Open Access article distributed under the terms of the Creative Commons Attribution Non-Commercial License (http:// creativecommons.org/licenses/by-nc/3.0) which permits unrestricted non-commercial use, distribution, and reproduction in any medium, provided the original work is properly cited. 
cies because of its assumed ability to increase yield by channeling the energy required from gonadal development to somatic growth (Tave, 1993). More importantly, it generates fish that are unable to breed and contribute to the local gene pool if they were to accidentally escape from confinement. By conferring sterility of exotic fish for a limited purpose, triploidy can serve as an effective method for reducing or eliminating the environmental risks of genetically modified organisms (Kim et al., 1994).

Numerous studies concerning the growth rates of triploid fish have been published. Growth rates tend to slow or cease in maturing fish, and it is during the later stages of sexual maturation that a growth advantage of triploid fish over diploids is most likely to be observed (Hatanaka et al., 1991; Kobayashi, 1992; Benfey, 1999). In species that survive spawning, diploids frequently exhibit compensatory growth and may overcome any disadvantage (Benfey, 1999). Therefore, a growth advantage of triploids is most likely to be seen in species where the diploids have high or complete mortality associated with sexual maturation and spawning, as in ayu (Plecoglossus altivelis) and twicespawned rainbow trout (Oncorhynchus mykiss) (Hatanaka et al., 1991; Kobayashi, 1992). Thyroid stimulating hormone (TSH) and thyroxine (T4) play indispensable roles during the embryonic and larval periods of fish development (Khalil et al., 2011). Because of the potentiating effects of TSH and T4 on fish larval growth and survival, it is important to investigate whether application of exogenous thyroid stimulating hormone and thyroxine to female brood fish results in better growth and survival of larvae (Khalil et al., 2011).

No previous study of the marine medaka has included a comparative analysis of the diploid and triploid fish. Therefore, we undertook a comparative analysis of the comparative study of growth and gonad maturation in diploid and triploid marine medaka, Oryzias dancena. So, the objectives of this study were to evaluate the reproductive characteristics of the triploid form of this species.

\section{MATERIALS AND METHODS}

The specimens of marine medaka, Oryzias dancena used in this study were from a laboratory stock maintained at the Institute of Marine Living Modified Organisms (iMLMO), Pukyong National University, Busan, Korea. The general maintenance of the experimental fish was according to the method of Song et al. (2009). Breeding occurred in brackish water ( 5 psu), as described by Cho et al. (2010). The breeding conditions included a temperature of $25 \pm 1^{\circ} \mathrm{C}$ and a 16 $\mathrm{h}$ light:8 h dark cycle. Triploid and diploid specimens were fed brine shrimp (Artemia nauplii; INVE, Salt Lake City, Utah, USA) and micro-particle feed (150-500 $\mu \mathrm{m}$ diameter; Ewha Oil Co., Busan, Korea).

Fertilized eggs were obtained each day by mating male and female broodfish in a glass tank containing $30 \mathrm{~L}$ of well-aerated water. The eggs were collected from females immediately following fertilization. At $2 \mathrm{~min}$ after fertilization the fertilized eggs were subjected to a cold shock treatment at $0^{\circ} \mathrm{C}$ for $45 \mathrm{~min}$. Following treatment the eggs were placed in a $25^{\circ} \mathrm{C}$ incubator until they hatched. The hatching success and the incidence of abnormal larvae were assessed based on stereoscopic microscope (C-DS; Nikon Co., Tokyo, Japan) examination of at least 23 eggs per group. The values for these parameters in the experimental treatments were expressed as percentages of treated eggs. After 60 days, triploid marine medaka were distinguished by flowcytometry and chromosome analysis.

Over 12 months the standard length, body weight, condition factor, and gonadosomatic index (GSI) for each individual 120 were measured to investigate the growth and maturation of diploid and triploid fish. The condition factor was determined using the equation: condition factor $=$ (body weight $\times 100) /\left(\right.$ body length) ${ }^{3}$, and the GSI was determined using the equation: GSI $=$ (gonad weight/body weight $) \times 100$. Sex hormone and growth hormone were 
analyzed through the plasma of each ploidy group at 120 days after hatching. The estradiol-17ß and testosterone concentrations were measured using fluorophotometry method while 48 hrs (i-Chroma, Sun Kyung Medical, Korea). To measure the concentrations of estradiol-17ß and testosterone, draw a $75 \mathrm{uL}$ of serum and add it to the detector buffer. Next, mix a specimen with buffer by voltex mixer and leave to the specimen at room temperature for $15 \mathrm{~min}$, finally, insert it to the i-Chroma reader.

To investigate changes in growth hormone levels, the concentrations of thyroid stimulating hormone (TSH) and thyroxine (T4) in samples of each group were measured using fluorophotometry during the 12 months following hatching. To measure the concentrations of TSH and T4, draw a $10 \mu \mathrm{L}$ of serum and add it to the detector buffer. Next, mix a specimen with buffer by voltex mixer and leave to the specimen at room temperature for $10 \mathrm{~min}$, finally, insert it to the i-Chroma reader.

The gonad morphology was observed in one-year-old diploid and triploid males and females. The gonads were surgically removed and fixed in buffered $10 \%$ formaldehyde solution for histological analysis, following morphological analysis. Conventional histological techniques were used to assess gonad development, including embedding in paraffin wax, sectioning to $6 \mu \mathrm{m}$ thickness, and staining using Mayer's hematoxylin and eosin.

The standard length, body weight, condition factor, and GSI were assessed using ANOVA followed by Duncan's multiple range test at the significance level $P=0.05$.

\section{RESULTS}

The von Bertalanffy growth parameters for diploid and triploid marine medaka, Oryzias dancena estimated using the non-linear regression method, are shown in Fig. 1. The von Bertalanffy growth equations were $L_{t}=30.2\left(1-e^{-3.22(t-}\right.$ $\left.{ }^{0.01)}\right)$ and $L_{t}=30.9\left(1-e^{-3.08(t-0.02)}\right)$ for the diploid and triploid females, respectively. The growth coefficients $(K)$ for the
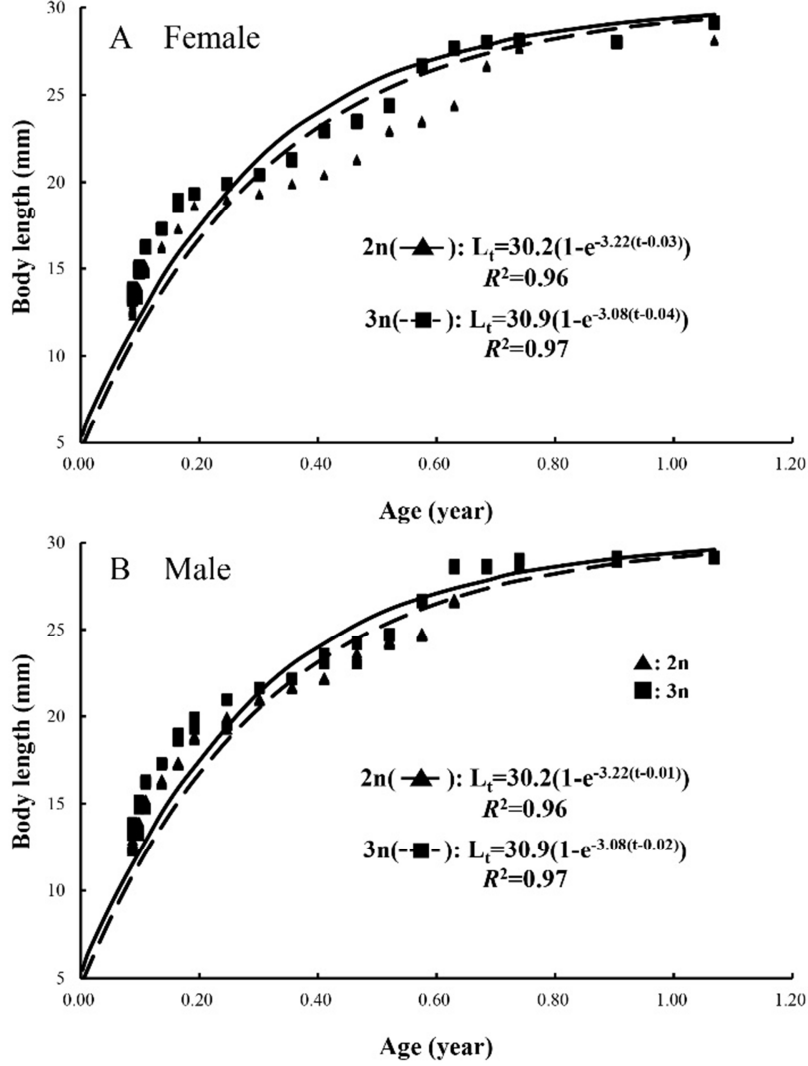

Fig. 1. The von bertalanffy growth curve on diploid and triploid marine medaka, Oryzias dancena in this experiment. Each values are means \pm S.D. of triplicate experiment.

diploid and triploid females were estimated to be 3.22/year and 3.08/year, respectively, their asymptotic maximum length $\left(L_{\infty}\right)$ was estimated to be $30.2 \mathrm{~mm}$ and $30.9 \mathrm{~mm}$, respectively, and the theoretical age at zero length $\left(t_{0}\right)$ was estimated to be -0.03 and -0.04 , respectively. The von Bertalanffy growth equations were $L_{t}=30.2\left(1-e^{-3.22(t-0.01)}\right)$ and $L_{t}=30.9\left(1-e^{-3.08(t-0.02)}\right)$ for the diploid and triploid males, respectively. The $\mathrm{K}$ and $\mathrm{L}_{\infty}$ values for the diploid and triploid males were similar to those of the females. The $t_{0}$ values differed between the diploid and triploid males $(-0.01$ and -0.02 , respectively), and was greater than that for the females. For each measured parameter, significant differences were found between the diploids and triploids, and the males and females $(P<0.05)$. 
The change in body weight for diploid and triploid marine medaka is shown in Fig. 2. During the experimental period the growth patterns for the diploids and triploids (female and male groups) were similar; all fish grew rapidly from 3 to 4 months of age, and grew slowly from 8 to 12 months of age. For both males and females the triploids were larger than their diploid counterparts during the experimental period. Among both diploid and triploid fish the body weight of males was greater than that of females. Fish condition was affected by ploidy, but not by gender $\mathrm{V}$ (Table $1 ; P<0.05$ ), and the condition of all groups decreased rapidly from 1 to 2 months of age. Up to 4 months of age the condition factor for both the male and female diploids was significantly higher than for their triploid counterparts. However, after 4 months of age the condition factor for both male and female groups was not significantly different between the diploid and triploid fish. During the experimental period, the condition factor within the
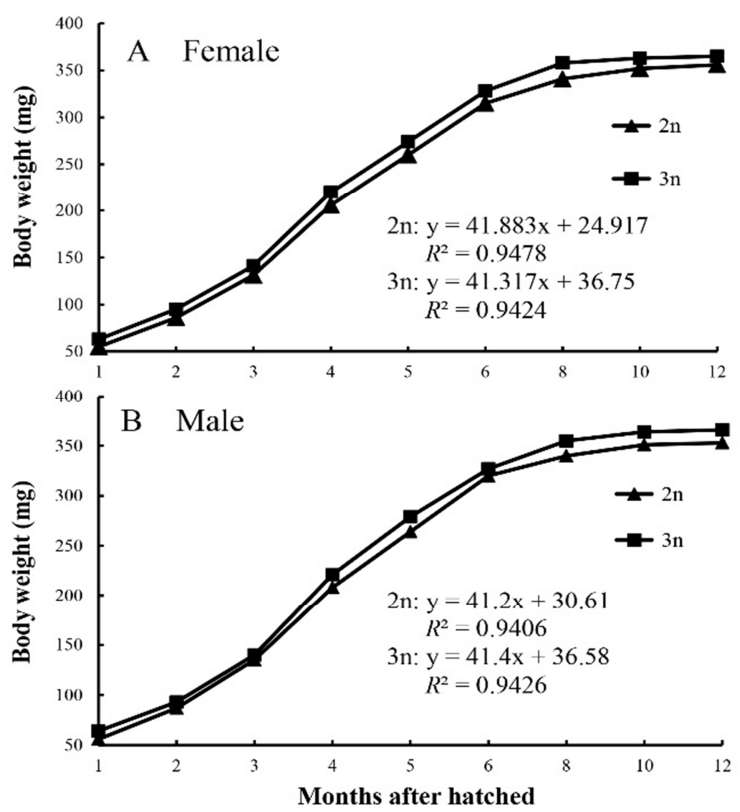

Fig. 2. Change of body weight on diploid and triploid marine medaka, Oryzias dancena during this experiment. Each values are means \pm S.D. of triplicate experiment.

Table 1. Change of condition factor on diploid and triploid marine medaka, Oryzias dancena during experiment*

\begin{tabular}{|c|c|c|c|c|c|}
\hline \multirow{3}{*}{$\begin{array}{c}\text { Time } \\
\text { (months after } \\
\text { hatched) }\end{array}$} & \multicolumn{5}{|c|}{ Condition factor } \\
\hline & \multicolumn{3}{|c|}{ Diploid } & \multicolumn{2}{|c|}{ Triploid } \\
\hline & Male & & & Male & Female \\
\hline 1 & $51.2^{\mathrm{a}}$ & & & $39.6^{\mathrm{b}}$ & $39.0^{\mathrm{b}}$ \\
\hline 2 & $6.32^{\mathrm{a}}$ & & & $5.67^{\mathrm{b}}$ & $5.78^{\mathrm{a}}$ \\
\hline 3 & $3.07^{\mathrm{a}}$ & & & $2.80^{\mathrm{b}}$ & $2.82^{\mathrm{b}}$ \\
\hline 4 & $2.42^{\mathrm{a}}$ & & & $2.26^{\mathrm{b}}$ & $2.24^{\mathrm{b}}$ \\
\hline 5 & $2.07^{\mathrm{a}}$ & & & $1.90^{\mathrm{a}}$ & $1.93^{\mathrm{a}}$ \\
\hline 6 & $1.95^{\mathrm{a}}$ & & & $1.82^{\mathrm{a}}$ & $1.83^{\mathrm{a}}$ \\
\hline 8 & $1.58^{\mathrm{a}}$ & & & $1.52^{\mathrm{a}}$ & $1.58^{\mathrm{a}}$ \\
\hline 10 & $1.47^{\mathrm{a}}$ & & & $1.47^{\mathrm{a}}$ & $1.47^{\mathrm{a}}$ \\
\hline \multirow[t]{2}{*}{12} & $1.39^{\mathrm{a}}$ & & & $1.40^{\mathrm{a}}$ & $1.41^{\mathrm{a}}$ \\
\hline & $\mathrm{DF}$ & Anova SS & Mean square & $F$-value & $P$-value \\
\hline Ploid & 1 & $30,512.581$ & $7,783.904$ & 259.349 & $<0.0001$ \\
\hline Sex & 3 & 254.017 & 14.127 & 001.448 & $<0.9589$ \\
\hline Interaction & 7 & $4,144.312$ & $1,038.084$ & 011.874 & $<0.0942$ \\
\hline
\end{tabular}

${ }^{*}$ Condition factor $=($ Body weight $\times 100) /(\text { Body length })^{3}$. Each values are means \pm S.D. of triplicate experiment. The different superscripts of each value are significantly different between ploid and $\operatorname{sex}(P<0.05)$. 
diploid and triploid groups did not differ significantly between females and males.

Changes in the GSI for diploid and triploid marine medaka are shown in Fig. 3. The GSI for triploid females and males was lower than that for their diploid counterparts, and within each ploidy group the GSI for females was higher than that for males. Changes in the GSI followed a similar pattern in all groups. The GSI of triploid females increased from $3.17 \%$ at 1 month following hatching to $20.45 \%$ at 4 months $(P<0.05)$, and decreased to $15.43 \%$ at 12 months. The GSI of triploid males increased from $1.56 \%$ at 1 month following hatching to $9.05 \%$ at 4 months $(P<0.05)$, and decreased to $7.18 \%$ at 12 months. For all groups the GSI was highest at 4 months, and decreased from 4 to 12 months. Morphological and histological analyses of the gonads of one-year-old fish showed that the triploid genotype caused significant depression of gonad development in marine medaka. The ovaries of the diploid females were well developed, with fully yolk-laden eggs, whereas those of the triploid females were poorly developed and significantly smaller than in the diploid fish (Fig. 4a and 4b). In contrast, there was no clear visual difference in the testicular morphology of diploid and triploid males, although the testes of

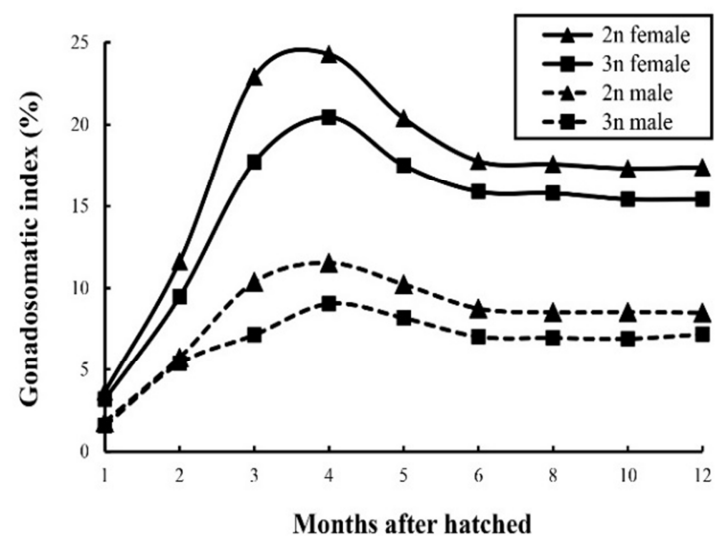

Fig. 3. Change of gonadosomatic index (GSI) on diploid and triploid marine medaka, Oryzias dancena during this experiment. $\mathrm{GSI}=(\operatorname{gonad} w e i g h t /$ body weight $) \times 100$. Each values are means \pm S.D. of triplicate experiment.

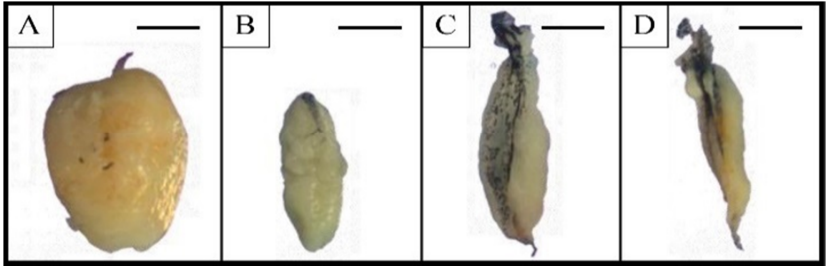

Fig. 4. External morphology of gonads from diploid and triploid marine medaka, Oryzias dancena. (A): diploid ovary; (B): triploid ovary; (C): diploid testis; (D): triploid testis. Bars indicate $1 \mathrm{~mm}$.

the triploid fish were slightly smaller, suggesting that the GSI of the triploid males differed from that of their diploid counterparts (Fig. 4c and 4d).

Histological analysis of the gonads showed clear differences between the diploid and triploid females. Unlike the diploid fish, which had highly developed ovaries filled with mature yolk-containing oocytes, the ovaries of the triploid females contained a considerable number of oogonia, with very few oocytes at the chromatin-nucleolus stage in the mesenchymal tissue (Fig. 5a and 5b). In addi-

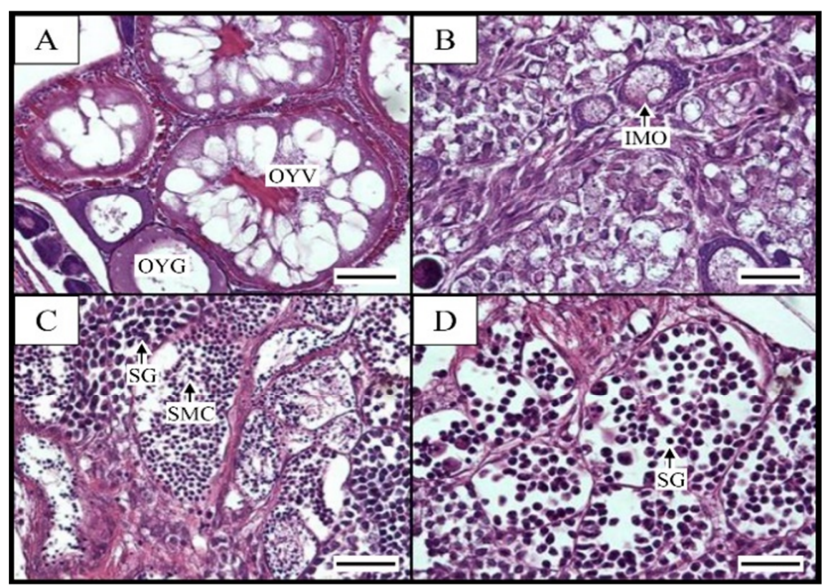

Fig. 5. Transverse sections of diploid and triploid marine medaka, Oryzias dancena. gonads: (A) diploid ovary; (B) triploid ovary; (C) diploid testis; (D) triploid testis. IMO: immature oocyte; OYG: oocyte in yolk granule stage; OYV: oocyte in yolk vesicle stage; SG: spermatogonium; SMC: spermatocyte. Bars indicate $50 \mu \mathrm{m}$. 
tion, the triploid males showed depressed gonad development compared with their diploid counterparts, even though the gross morphology of the diploid and triploid testes was not significantly different. Normal spermatids and sperm were present in the testes of the diploid fish, whereas the testes of the triploid males had few spermatids or no sperm (Fig. 5c and 5d).

The concentrations of thyroid stimulating hormone and thyroxine were affected by the ploidy of fish, but not by their gender (Table 2; $P<0.05$ ). The concentration of thyroid stimulating hormone and thyroxine in all groups in- creased slowly during the experimental period. In both the diploid and triploid groups the concentrations of these two hormones were lower in the females than in the males, but for both genders were higher in triploid fish than in the diploids. As shown in Fig. 6, the testosterone concentration in the diploid fish gradually decreased after the experiment. At $24 \mathrm{~h}$, values of testosterone restored initial value, and at $48 \mathrm{~h}$ the testosterone concentration was similar to that at 0 and $24 \mathrm{~h}$. However, the triploids had lower testosterone concentrations than the diploids because of their lower GSI $(P<0.05$; Fig. 6). The estradiol-17ß concentra-

Table 2. Comparative analysis of thyroid stimulating hormone and thyroxine between ploid and sex on marine medaka, Oryzias dancena*

\begin{tabular}{|c|c|c|c|c|c|c|c|c|}
\hline \multirow{3}{*}{$\begin{array}{c}\text { Time } \\
\text { (months after } \\
\text { hatched) }\end{array}$} & \multicolumn{4}{|c|}{$\begin{array}{l}\text { Thyroid stimulating hormone } \\
\qquad(\mu \mathrm{IU} / \mathrm{L})\end{array}$} & \multicolumn{4}{|c|}{ Thyroxine $(\mu \mathrm{g} / \mathrm{dL})$} \\
\hline & \multicolumn{2}{|c|}{ Diploid } & \multicolumn{2}{|c|}{ Triploid } & \multicolumn{2}{|c|}{ Diploid } & \multicolumn{2}{|c|}{ Triploid } \\
\hline & Male & Female & Male & Female & Male & Female & Male & Female \\
\hline 1 & $3.1^{\mathrm{a}}$ & $2.8^{\mathrm{a}}$ & $3.9^{\mathrm{b}}$ & $3.4^{\mathrm{b}}$ & $3.8^{1}$ & $3.7^{1}$ & $4.3^{2}$ & $4.2^{2}$ \\
\hline 2 & $3.2^{\mathrm{a}}$ & $2.9^{\mathrm{a}}$ & $4.0^{\mathrm{b}}$ & $3.5^{\mathrm{b}}$ & $4.2^{1}$ & $4.1^{1}$ & $4.6^{2}$ & $4.5^{2}$ \\
\hline 3 & $3.4^{\mathrm{a}}$ & $3.0^{\mathrm{a}}$ & $4.1^{b}$ & $3.7^{\mathrm{b}}$ & $4.7^{1}$ & $4.7^{1}$ & $5.0^{2}$ & $5.1^{2}$ \\
\hline 4 & $3.6^{\mathrm{a}}$ & $3.2^{\mathrm{a}}$ & $4.3^{\mathrm{b}}$ & $3.9^{\mathrm{b}}$ & $5.1^{1}$ & $4.9^{1}$ & $5.3^{2}$ & $5.3^{2}$ \\
\hline 5 & $3.9^{\mathrm{a}}$ & $3.5^{\mathrm{a}}$ & $4.6^{b}$ & $4.3^{\mathrm{b}}$ & $5.2^{1}$ & $5.1^{1}$ & $5.6^{2}$ & $5.7^{2}$ \\
\hline 6 & $4.1^{\mathrm{a}}$ & $3.7^{\mathrm{a}}$ & $4.8^{\mathrm{b}}$ & $4.6^{\mathrm{b}}$ & $5.7^{1}$ & $5.7^{1}$ & $6.3^{2}$ & $6.3^{2}$ \\
\hline 8 & $4.6^{\mathrm{a}}$ & $4.1^{\mathrm{a}}$ & $5.3^{\mathrm{b}}$ & $4.9^{\mathrm{b}}$ & $6.1^{1}$ & $5.9^{1}$ & $6.5^{2}$ & $6.4^{2}$ \\
\hline 10 & $4.6^{\mathrm{a}}$ & $4.2^{\mathrm{a}}$ & $5.1^{\mathrm{db}}$ & $5.0^{\mathrm{b}}$ & $6.3^{1}$ & $6.2^{1}$ & $7.6^{2}$ & $7.4^{2}$ \\
\hline 12 & $4.6^{\mathrm{a}}$ & $4.1^{\mathrm{a}}$ & $5.2^{\mathrm{b}}$ & $5.1^{\mathrm{b}}$ & $6.3^{1}$ & $6.3^{1}$ & $8.7^{2}$ & $8.6^{2}$ \\
\hline \multicolumn{9}{|c|}{ Throid stimulating hormone } \\
\hline & \multicolumn{2}{|l|}{ DF } & Anova SS & \multicolumn{2}{|c|}{ Mean square } & $F$-value & \multicolumn{2}{|c|}{$P$-value } \\
\hline Ploid & \multicolumn{2}{|l|}{1} & $30,475.440$ & \multicolumn{2}{|c|}{$7,618.860$} & 248.055 & \multicolumn{2}{|c|}{$<0.0001$} \\
\hline Sex & \multicolumn{2}{|l|}{3} & 438.095 & \multicolumn{2}{|c|}{54.049} & 7.612 & \multicolumn{2}{|c|}{$<0.9024$} \\
\hline Interaction & \multicolumn{2}{|l|}{7} & $5,762.451$ & \multicolumn{2}{|c|}{$1,382.093$} & 29.588 & \multicolumn{2}{|c|}{$<0.0459$} \\
\hline \multicolumn{9}{|c|}{ Thyroxine } \\
\hline & \multicolumn{2}{|l|}{$\mathrm{DF}$} & Anova SS & \multicolumn{2}{|c|}{ Mean square } & $F$-value & \multicolumn{2}{|c|}{$P$-value } \\
\hline Ploid & \multicolumn{2}{|l|}{1} & $34,259.1$ & \multicolumn{2}{|c|}{$67,591.4$} & 548.4 & \multicolumn{2}{|c|}{$<0.0001$} \\
\hline Sex & \multicolumn{2}{|l|}{3} & $5,711.0$ & \multicolumn{2}{|c|}{896.1} & 16.2 & \multicolumn{2}{|c|}{$<0.7841$} \\
\hline Interaction & \multicolumn{2}{|l|}{7} & $45,867.5$ & \multicolumn{2}{|c|}{$12,438.1$} & 121.5 & \multicolumn{2}{|c|}{$<0.0446$} \\
\hline
\end{tabular}

${ }^{*}$ Each values are means \pm S.D. of triplicate experiment. Differences between ploid and sex/stage are significant at this level $(P<0.05)$. 


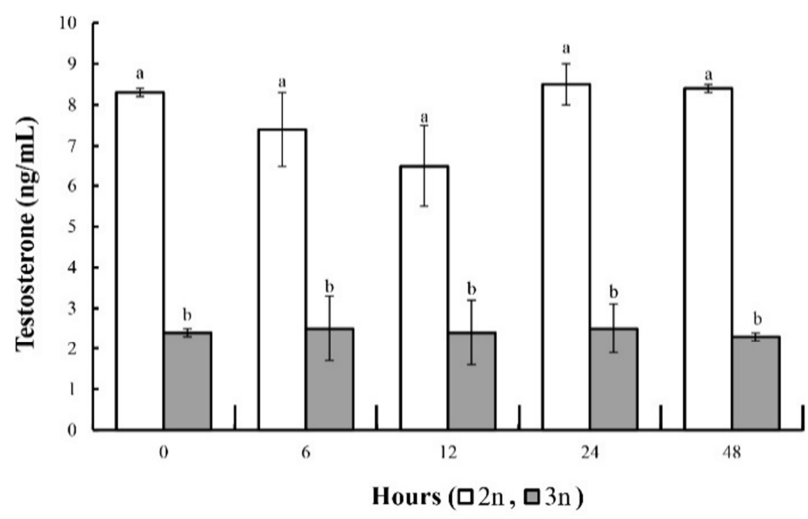

Fig. 6. Changed testosterone in diploid and triploid male marine medaka, Oryzias dancena while 48 hrs. Each values are means \pm S.D. of triplicate experiment. Different letters on error bars are significantly different for each group $(P<0.05)$.

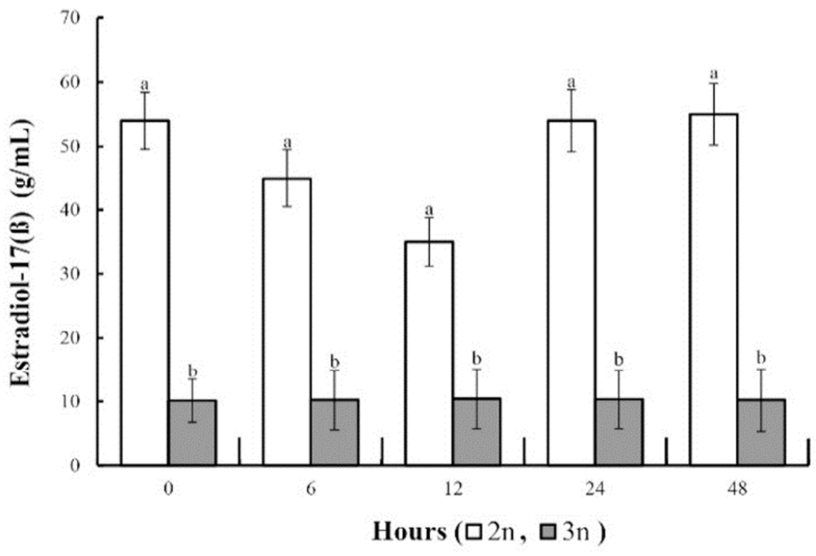

Fig. 7. Change of estradiol-17ß in diploid and triploid female marine medaka, Oryzias dancena while 48 hrs. Each values are means \pm S.D. of triplicate experiment. Different letters on error bars are significantly different for each group $(P<0.05)$.

tion in the diploid fish showed a tendency to gradually decrease from 6 to $12 \mathrm{~h}$ (Fig. 7). However, at 24 and $48 \mathrm{~h}$ the estradiol-17ß concentration had returned to the level at $0 \mathrm{~h}$. In the triploids the estradiol-17ß concentration did not change, and the concentrations of testosterone and estradiol-17ß in the induced triploids was significantly less than in the diploids $(P<0.05$; Fig. 10).

\section{DISCUSSION}

The triploid marine medaka, Oryzias dancena grew more rapidly than their diploid counterparts $(P<0.05)$, which is consistent with the results of previous studies. Nam et al. (2001) reported that triploid mud loach had a growth rate 22 25 times that of diploid fish. In this study the triploid marine medaka were larger than the diploid form, but giantism of the triploid was not responsible. Kim et al. (2001) \& Seol et al. (2008) suggested that the absence of giantism in triploids is because of their smaller cell number. In the present study the male marine medaka (diploid and triploid) were larger than the females $(P<0.05)$. Female fish are typically larger than male fish of the same age, although in some species the reverse is true; examples include the gudgeon, Gobio gobio (Mann, 1980) \& the filefish, Brachaluteres ulvarum (Akagawa et al., 1995). The reasons for these size differences are unclear (Katano, 1998). It has been suggested in several studies that the evolution of a larger body size in males probably results from male-male competition associated with a polygynous mating systems (Katano, 1998; Kim et al., 2008). Therefore, exploring the nature and extent of sexual dimorphism can extend our understanding of social structure and adaptation, as well as species identification. Over 1 month we found that a rapid increase in length caused a reduction in condition, as measured using the condition factor, and the condition factor for triploids was lower than that for the diploids. Unfortunately, no previous studies have reported such a rapid decrease in condition, or differences in the condition factor between diploid and triploid marine medaka or other fish species, so our observations remain unexplained.

Morphological and histological analyses of triploid gonads probably causes sterility in this species. The odd chromosome number induced during triploidization precludes homologous chromosomal pairing during meiosis I, which leads to inefficient gamete differentiation and consequently confers sterility on the triploid fish (Zhang et al., 2005). Overall, most of our 
observations of the gonads in this study were similar to those previously reported for other triploid fish: smaller gonads, significantly delayed gonadal development, and more pronounced sterility in females (Kim et al., 1994; Felip et al., 1999; Tiwary et al., 2000; Feindel et al., 2011). In a recent study Cal et al. (2010) reported that the induction of triploidy lowered the estradiol- $17 ß$ concentration and changed its internal secretion, resulting in oogenesis disorders. However, numerous previous studies have also claimed that triploid fish, especially old triploid males, may have a functional but reduced capacity to reproduce, despite their sterile-like gonadal development (Benfey, 1999). The artificial insemination of normal haploid eggs of tench (Tinca tinca) using sperm from triploid fish has been reported to produce some abnormal larvae (Linhart et al., 2006). In a recent study, Karami et al. (2011) reported that treatment of triploid African catfish (Clarias gariepinus) with the ovulation/ spermiating agent Ovaprim induced advanced vitellogenin sequestration in triploid oocytes, and promoted the fertilization capacity of milt from triploid males.

Sex hormones, including testosterone and estradiol-17ß, are commonly found in induced triploids because their testes and ovaries don't mature (Kim et al., 1994; Park \& Kim, 1994). Unlike the normal gonadal maturation of diploids, in induced triploids the gonads are immature on formal and histological (Lincoln \& Scott, 1984; Kim et al., 1994), and induced triploids showed lower concentrations of sex hormones because of decreased hormone secretion resulting from immaturity (Lincoln, 1981; Lincoln \& Scott, 1984). The testes of diploids had normal spermatids and spermatozoa, while few were seen in the induced triploids, and the ovaries of diploids had many well developed oocytes, while those of the induced triploids exhibited oogonia (Kim et al., 1994; Park \& Kim, 1994; Kim et al., 2001).

The concentrations of thyroid stimulating hormone (TSH) and thyroxine (T4) were found to be higher in the induced triploid fish over 1 year $(P<0.05)$. In both the diploid and triploid groups the concentrations of TSH and T4 were higher in males than in females. In previous studies the initial survival of freshwater fish, transformation, and the effects of TSH and T4 on development and growth have been observed (Lam \& Sharma, 1985; Weatherley \& Gill, 1987). Administration of growth hormone caused a reduction in the weight to length ratio (condition factor) in diploids but not in triploids, and caused triploids to deplete lipid energy stores more rapidly (McLean et al., 1991). In our experiment the induced triploids were expected to show better growth compared with the diploids, and the condition factor for the latter was expected to decrease faster. As no comparable studies have investigated differences in TSH and T4 between diploid and triploid in marine medaka or other fish species, no explanation for our observations is available. Although induced triploids are infertile, their production is economically feasible because they grow faster than their diploid counterparts. Further studies will be necessary to achieve stable production of triploids. In particular, longer-term observations of the potential for maturation in older triploid marine medaka should extend our understanding of their reproductive capacity.

\section{ACKNOWLEDGEMENTS}

The comments of the anonymous reviewers greatly improved the quality of this manuscript. All experiments in this study complied with the current laws of Korea (the Law Regarding Experimental Animals, No. 9932). This study was conducted as part of LMO safety management studies for ocean and fisheries in 2015 supported by the Ministry of Maritime Affairs and Fisheries of Korea.

\section{REFERENCES}

Akagawa I, Tsukamoto Y, Okiyama M (1995) Sexual dimorphism and pair spawning into a sponge by the filefish, Brachaluteres ulvarum, with a description of 
the eggs and larvae. Jpn J Ichthyol 41:397-407.

Benfey TJ (1999) The physiology and behavior of triploid fishes. Rev Fisher Sci 7:39-67.

Cal R, Terrones J, Vidal S, Martínez P, Piferrer F (2010) Differential incidence of gonadal apotosis in triploidinduced male and female turbot (Scophthalmus maxi$m u s)$. Aquaculture 307:193-200.

Cho YS, Lee SY, Kim DS, Nam YK (2010) Tolerance capacity to salinity changes in adult and larva of Oryzias dancena, a euryhaline medaka. Kor J Ichthyol 22:9-16.

Cho YS, Lee SY, Kim DS, Nam YK (2012) Characterization of stablefluorescent transgenic marine medaka (Oryzias dancena) lines carrying red fluorescent protein gene driven by myosin light chain 2 promoter. Transgenic Res 22:849-859.

Cho YS, Lee SY, Kim YK, Kim DS, Nam YK (2011) Functional ability of cytoskeletal $\beta$-actin regulator to drive constitutive and ubiquitous expression of a fluorescent reporter throughout the life cycle of transgenic marine medaka, Oryzias dancena. Transgenic Res 20:1333-1355.

Don J \& Avtalion RR (1986) The induction of triploidy in Oreochromis aureus by heat shock. Theoretic Appl Genetics 72:186-192.

Feindel NJ, Benfey TJ, Trippel EA (2011) Gonadal development of triploid Atlantic cod, Gadus morhua. J Fish Biol 78:1900-1912.

Felip A, Zanuy S, Carrillo M, Piferrer F (1999) Growth and gonadal development in triploid sea bass (Dicentrarchus labrax L) during the first two years of age. Aquaculture 173:389-399.

Hatanaka H, Inada Y, Taniguchi N (1991) Growth and maturation of triploid ayu, Plecoglossus altivelis in the pre- and post-spawning seasons. Suisanzoshoku 39: 241-247.

Inoue K, Takei Y (2003) Asian medaka fishes offer new models for studying mechanisms of seawater adapta- tion. Comp Biochem Physiol Part B 136:635-645.

Kang CK, Tsai SC, Lee TH, Hwang PP (2008) Differential expression of branchial $\mathrm{Na}^{+} / \mathrm{K}^{+}$-ATPase of two medaka species, Oryzias latipes and Oryzias dancena, with different salinity tolerances acclimated to fresh water, brackish water and seawater. Comp Biochem Physiol Part A 151:566-575.

Karami A, Chirstianus A, Zokaeifar H, Saad KZ, Imraan FTJ, Shakibazadeh S, Negarestan H, Courtenay SC (2011) Ovaprim treatment promotes oocyte development and milt fertilization rate in diploid and triploid African catfish (Clarias gariepinus). Aquacult Int 19: $1025-1034$

Katano O (1998) Growth of dark chub, Zacco temmincki (Cyprinidae), with a discussion of sexual size differences. Environ Biol Fish 52:305-312.

Khalil NA, Khalaf Allah, HMM, Mousa MA. (2011) The effect of maternal thyroxine injection on growth, survival and development of digestive system of Nile tilapia, Oreochromis niloticus, larvae. Adv Biosci Biotechnol 2:320-329.

Kim DS, Cho HJ, Park IS, Choi GC, Nam YK (2001) Cytogenetic traits and gonad development of induced triploidy in far eastern catfish, Silurus asotus. Kor J Genet 23:55-62.

Kim DS, Jo JY, Lee TY (1994) Induction of triploidy in mud loach (Misgurnus mizolepis) and its effect on gonad development and growth. Aquaculture 120:263270 .

Kim DS, Nam YK, Park IS (1995) Survival and karyological analysis of reciprocal diploid and triploid hybrids between mud loach (Misgurunus mizolepis) and cyprinid loach (Misgurunus anguillicaudatus). Aquaculture 135:257-266.

Kim YJ, Zhang CI, Park I-S, Na JH, Olin P (2008) Sexual dimorphism in morphometric characteristics of Korean chub, Zacco koreanus (Pisces, Cyprinidae). J Ecol 
Field Biol 31:107-113.

Kobayashi T (1992) Growth, survival and reproductive cycle of induced triploid rainbow trout under the communal rearing condition with diploid for long period. Suisanzoshoku 40:57-70.

Lam TJ, Sharma R (1985) Effects of salinity and thyroxine on laval survival, growth and development in the carp, Cyprinus carpio. Aquaculture 44:201-212.

Lemoine HL Jr, Smith LT (1980) Polyploidy induced in brook trout by cold shock. Trans Amer Fisher Soc 109:626-631.

Lincoln RF \& Scott AP (1984) Sexual maturation in triploid rainbow trout, Salmo gairdneri Richardson. J Fish Biol 25:385-392.

Lincoln RF (1981) The growth of female diploid and triploid plaice (Pleuronectes platessa) and plaice $\times$ flounder (Platichthys flesus) hybrids over one spawning season. Aquaculture 25:259-392.

Linhart O, Rodina M, Flajshans M, Mavrodiev N, Nebesarova J, Gela D, Kocour M (2006) Studies on sperm of diploid and triploid tench, Tinca tinca (L.). Aquacult Int 14:9-25.

Mann RHK (1980) The growth and reproductive strategy of the gudgeon, Gobio gobio (L.), in two hard-water rivers in Southern England. J Fish Biol 17:163-176.

McLean E, Sadar MD, Devlin RH, Souza LM, Donaldson EM. (1991) Promotion of growth in diploid and triploid coho salmon with parenteral delivery of a recombinant porcine somatotropin. Aquat Liv Res 4:155-160.

Nam YK, Cho HJ, Cho YS, Noh JK, Kim CG, Kim DS
(2001) Accelerated growth, gigantism and likely sterility in autotransgenic triploid mud loach Misgurnus mizolepis. J World Aquacult Soc 32:353-363.

Nam YK, Choi GC, Kim DS (1999) Blocking of the 1st cleavage in mud loach (Misgurnus mizolepis). Kor. J. Aquacult 12:167-173.

Park I-S, Kim DS (2000) Comparison of some tissues in diploid and induced triploid hybrid between mud loach, Misgurnus mizolepis and cyprinid loach, M. anguillicaudatus. Dev Reprod 4:19-28.

Park I-S, Kim HB (1994) Induction of triploid cherry salmon, Oncorhyncus masou. J Aquacult 7:207-223.

Seol DW, Im SY, Hur WJ, Park MO, Kim DS, Jo JY, Park I-S (2008) Haematological parameters and respiratory function in diploid and triploid Far Eastern catfish, Silurus asotus. Genes and Genomics 30:205-213.

Song HY, Bang IC, Nam YK, Kim DS (2009) Embryogenesis and early ontogenesis of a marine medaka, Oryzias dancena. Kor J Ichthyol 21:227-238.

Tave D (1993) Growth of triploid and diploid bighead carp (Hypophthalmichthys nobilis). J Appl Aquacult 2:13-25.

Tiwary BK, Kirubagaran R, Ray AK (2000) Gonadal development in triploid Heteropneustes fossilis. J Fish Biol 57:1343-1348.

Weatherley AH, Gill HS (1987) The Biology of Fish Growth, 6. Influence of Hormones. Academic Press pp: 201-204.

Zhang C, He XX, Liu SJ, Sun YD, Liu Y (2005) Chromosome pairing in meiosis I in allotetraploid hybrids and allotriploid crucain carp. Acta Zool Sin 51:89-94. 